8 - ORIGINAL ARTICLE

EXPERIMENTAL SURGICAL INFECTIONS

\title{
Copaiba oil effect on induced fecal peritonitis in rats $^{1}$
}

\author{
Letícia Nobre Lopesi, Felipe Augusto Folha Santos ${ }^{\mathrm{II}}$, Louize Caroline Marques Oliveira ${ }^{\mathrm{III}}$, Sandro Percário ${ }^{\mathrm{IV}}$, Charles Alberto \\ Villacorta de Barros", Marcus Vinicius Henriques Brito ${ }^{\mathrm{VI}}$
}

DOI: http://dx.doi.org/10.1590/S0102-865020150080000008

I'Graduate student, Universidade Estadual do Pará (UEPA), Belem-PA, Brazil. Technical procedures, care of animals, interpretation of data, manuscript preparation.

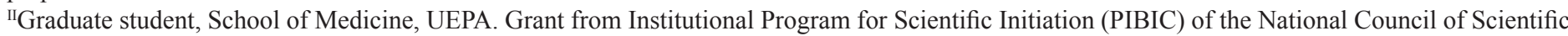
and Technological Development (CNPq) Ministry of Science, Technology and Inovation, Brazil. Technical procedures, statistical analysis, interpretation of data, manuscript preparation.

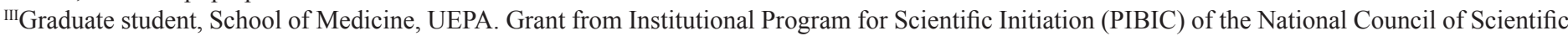
and Technological Development (CNPq) Ministry of Science, Technology and Inovation, Brazil. Care of animals, technical, manuscript preparation. ${ }^{\text {IV }} \mathrm{PhD}$, Associate Professor, School of Medicine, Universidade Federal do Para (UFPA), Brazil. Evaluation of oxidative stress.

${ }^{v} \mathrm{PhD}$, School of Medicine, UEPA, Belem-PA, Brazil. Design of the study, critical revision, final approved the manuscript.

${ }^{v I P h D}$, Full Professor, Head, Department of Integrate Health, School of Medicine, UEPA, Belem-PA, Brazil. Conception and design of the study, critical revision, final approved the manuscript.

\section{ABSTRACT}

PURPOSE: To evaluate the effects of copaiba oil as a prophylactic and/or therapeutic substance on survival of rats subjected to cecal ligation and puncture, describing histopathological and oxidative stress findings.

METHODS: Forty rats (Ratus norvegicus) were distributed into five study groups (N=8): Sham group (ShG): normal standard animals; Sepse group (SepG): submitted a cecal ligation and puncture (CLP); Pre group (PreG): administered copaiba oil once daily by subcutaneous injection for five days before carrying out CLP; Post CLP group (PostG): administered copaiba oil once daily by subcutaneous injection from the first day of CLP until death by sepsis; and Pre/Post group (Pre/PostG): administered copaiba oil once daily by subcutaneous injection for five days before carrying out CLP and from the first day of CLP until de death by sepsis. After the death of the animals, blood was collected for assessment of oxidative stress and histological analysis were performed. The Kaplan-Meier curves of surviving time were realized.

RESULTS: Survival analysis demonstrated that animals treated with copaiba oil prior to the execution of the CLP (PreG and Pre/Post groups) had longer survival compared to the sepsis group $(\mathrm{p}<0.0001)$ whereas animals receiving copaiba only after the completion of CLP (PostG) showed no statistically significant difference compared to the sepsis group. However, when comparing the two groups in which was administered copaiba previously (PreG and Pre/PostG groups), there was no statistical significance between the groups $(\mathrm{p}=0.4672)$. There was no statistical difference between histopathological findings or the levels of oxidative stress.

CONCLUSION: Prophylactic subcutaneous administration of copaiba increases survival of rats subjected to severe sepsis by cecal ligation and puncture.

Key words: Plants, Medicinal. Peritoneal Diseases. Fabaceae. Oils. Rats. 


\section{Introduction}

Peritonitis is one of the most frequent causes of sepsis and death in intensive care units. In peritonitis, sepsis occurs when an intra-abdominal infection site triggers a systemic response ${ }^{1}$. Sepsis is a complex syndrome related to a systemic inflammatory response with multiple manifestations that may cause the dysfunction or failure of one or more organs or even death ${ }^{2}$.

Severe sepsis and septic shock are major healthcare problems, affecting millions of people around the world each year $^{3}$, In the United States, severe sepsis is recorded in $2 \%$ of patients admitted to the hospital, The number of cases in the United States exceeds 750.000 per year and was recently reported to be rising ${ }^{4}$, resulting in 215.000 deaths per year. In the European Union members states, the statistics are not very different, with an estimated 150.000 deaths per year from sepsis ${ }^{5}$.

The first large study of sepsis conducted in Brazil was the Brazilian Sepsis Epidemiological Study (BASES), which demonstrated the incidence of sepsis in ICU patients was found to be $30.5 \%$. The mortality rate for patients with SIRS (from either sepsis or any other cause), sepsis, severe sepsis and septic shock was $24.2 \%, 33.9 \%, 46.9 \%$ and $52.2 \%$, respectively ${ }^{5}$.

The therapeutic approach to patients diagnosed with sepsis remains a medical challenge despite all of the recent advances $^{5}$. Treatment of patients with sepsis or septic shock is performed by antibiotics and drugs which interfere with cardiovascular alterations. However, it does not interfere with the inflammatory response, and this may be one of the high mortality patterns in patients with septic shock ${ }^{7}$.

The use of plants for medicinal purposes, for treatment, healing and disease prevention, is one of the oldest forms of medical practice of humanity ${ }^{8}$. The knowledge about medicinal plants symbolizes several times, the only therapeutic resource in many communities and ethnic groups ${ }^{9}$. According to WHO (World Health Organization), $65-80 \%$ of the population, especially in developing countries, still believe on products based on medicinal plants in the treatment their diseases ${ }^{10}$.

Even today, in several cities in Brazil, medicinal plants are sold in street markets and found in homes. Popular comments on the use and efficacy of medicinal plants contribute significantly to the dissemination of therapeutic virtues of plants, because of the medicinal effects they produce, despite not having many of its known chemical constituents ${ }^{9}$.

Among the species used, it has been copaiba oil, which consumed, either orally or topically, for medicinal purposes since the sixteenth century ${ }^{11}$. Several studies have demonstrated that this oil has anti-inflammatory, antitumoral, antioxidant ${ }^{9}$ and antimicrobial properties, more specifically against Gram-positive bacteria $^{12}$.

In addition to the proven antimicrobial potential ${ }^{12}$, there are reports in the literature that demonstrate the effectiveness of copaiba oil in the treatment of sepsis in mice and rats with subcutaneous oil administration ${ }^{13,14}$. Thus, the aim of this study is to evaluate the copaiba oil effect on fecal peritonitis induced in rats.

\section{Methods}

Before the start of the project, it was approved by the Ethics Committee in the Use of Animals of the Universidade Estadual do Pará (UEPA), protocol 22/14. Forty adults males Wistar rats (Ratus norvegicus) were used, weighing between 200 250grams, provided from the Animal Colony of the Experimental Surgery Laboratory of UEPA, kept in a controlled environment, with food and water ad libitum. The animals were randomized distributed into five groups, with eight animals each:

-Sham Group (ShG): The animals were used as normal standard for survival and histological analysis; the animals underwent the same surgical techniques, but without the performance of CLP;

-Sepsis Group (SepG): Animals were only realized the cecal ligation and puncture (CLP);

-Pre Group (PreG): Administered copaiba oil $(0.63 \mathrm{ml} /$ $\mathrm{kg} /$ day) once daily by subcutaneous injection for five days before carrying out cecal ligation and puncture (CLP) $)^{13,14}$;

-Post CLP Group (PostG): Administered copaiba oil $(0.63 \mathrm{ml} / \mathrm{kg} / \mathrm{day})$ once daily by subcutaneous injection from the first day of the CLP until the death by sepsis.

-Pre and Post CLP Group (Pre/PostG): Administered copaiba oil $(0,63 \mathrm{ml} / \mathrm{kg} /$ day $)$ once daily by subcutaneous injection for five days before carrying out CLP and from the first day of the CLP until the death by sepsis.

When performed, the copaiba injection was carried out on the dorsum of animals.

The animals were anesthetized with ketamine hydrochloride $(100 \mathrm{mg} / \mathrm{Kg})$ and xylazine hydrochloride $(10 \mathrm{mg} /$ $\mathrm{Kg}$ ), intraperitoneally. After was performed the epilation and antisepsis of the abdominal region. Subsequently, was performed a laparotomy of three centimeter.

Surgical procedures followed the same pattern described by Botelho et al. ${ }^{14}$ that consist in opening the abdominal cavity, locate, expose and isolate the cecum, leaving the rest of the small 
and large intestine into the peritoneal cavity, taking care not to violate or damage the mesenterials' vessels. To induce a highgrade sepsis, $75 \%$ of cecum was ligated with silk 4-0 just after the ileocecal valve. Cecal stump was transfixed by a single throughand-through puncture with a $21 \mathrm{G}$ needle. After the surgical procedure, was administered pre-heated saline $(5 \mathrm{ml}$ per $100 \mathrm{~g})$ by subcutaneously and dipirona $30 \mathrm{mg} / \mathrm{kg}$ for analgesia.

In this study was used the copaiba oil of Copaifera officinalis, donated by EMBRAPA (Brazilian Company of Agricultural Research) from seedlings provided by the garden of medicinal plants of this company.

Confirmed the death of the animals was collect the lung, kidney and liver of the animal, that were stored in $10 \%$ buffered formaldehyde and used for histopathological analysis by means of hematoxylin and eosin. It was made just a descriptive analysis of the organs.

Oxidative stress was verified by measuring the malondialdehyde (MDA), not being directly quantified inflammatory cytokines. The verification is performed using
$0.5 \mathrm{~mL}$ of plasma analysis, which is prepared by centrifugation at $2500 \mathrm{rpm}$ for 15 minutes. The collection was performed immediately after the death of the animal by cardiac puncture

Survival curves of groups were plotted using the KaplanMeier method and then compared by the log-rank test. KruskallWallis test was performed to compare the oxidative stress results. Was adopted a significance level of 5\% to reject the null hypothesis.

\section{Results}

Survival analysis demonstrated that animals treated with copaiba prior to the execution of the CLP (PreG and Pre/ PostG groups) had longer survival compared to the sepsis group $(p<0.0001)$ (Figure 1), whereas animals receiving copaiba only after the completion of CLP (PostG) showed no statistically significant difference compared to the sepsis group. However, when comparing the two groups in which was administered copaiba previously (PreG and Pre/PostG groups), there was no statistical significance between the groups $(\mathrm{p}=0.4672)$ (Tables 1 and 2$)$.

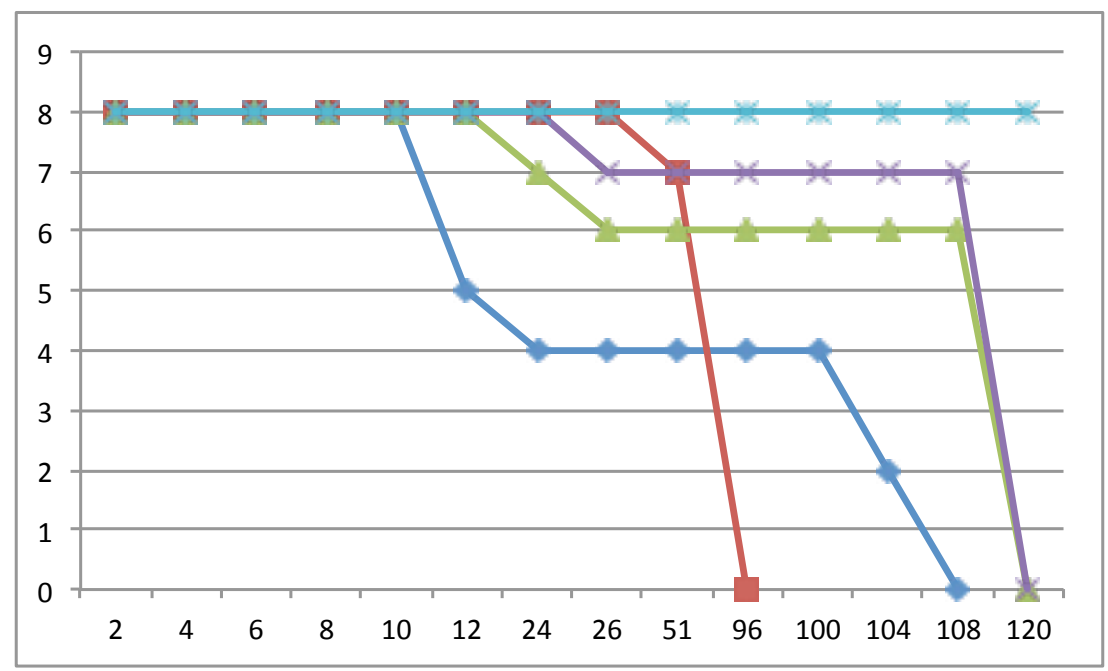

FIGURE 1 - Survival curve of animals after performing cecal ligation and puncture, according to the group, in hours. ${ }^{*} \mathrm{p}<0.05$. Log-Rank test.

TABLE 1 - Long-Rank test results of the study groups.

\begin{tabular}{|c|c|c|c|c|}
\hline Results & SepGXPreG & SepGXPostG & SepGXPre/PostG & PreGXPre/PostG \\
\hline Observed & 8 & 6 & 8 & 2 \\
\hline Expected & 2.3811 & 6.0326 & 2.2953 & 1.3897 \\
\hline Chi-square & 23.744 & 0.0007 & 24.1458 & 0.5286 \\
\hline Degrees of freedom & 1 & 1 & 1 & 1 \\
\hline
\end{tabular}


TABLE 2 - Survival data of study groups.

SepG

PostG

PreG

Pre/PostG

\begin{tabular}{|c|c|c|c|c|c|c|c|c|}
\hline Hours after & Alive & Occurrence & Alive & Occurrence & Alive & Occurrence & Alive & Occurrence \\
\hline 2 & 8 & 0 & 8 & 0 & 8 & 0 & 8 & 0 \\
\hline 4 & 8 & 0 & 8 & 0 & 8 & 0 & 8 & 0 \\
\hline 6 & 8 & 0 & 8 & 0 & 8 & 0 & 8 & 0 \\
\hline 8 & 8 & 0 & 8 & 0 & 8 & 0 & 8 & 0 \\
\hline 10 & 8 & 0 & 8 & 0 & 8 & 0 & 8 & 0 \\
\hline 12 & 5 & 3 & 8 & 0 & 8 & 0 & 8 & 0 \\
\hline 24 & 4 & 1 & 8 & 0 & 7 & 1 & 8 & 0 \\
\hline 26 & 4 & 0 & 8 & 0 & 6 & 1 & 7 & 1 \\
\hline 51 & 4 & 0 & 7 & 1 & 6 & 0 & 7 & 0 \\
\hline 96 & 4 & 0 & 0 & 7 & 6 & 0 & 7 & 0 \\
\hline 100 & 4 & 0 & 0 & 0 & 6 & 0 & 7 & 0 \\
\hline 104 & 2 & 2 & 0 & 0 & 6 & 0 & 7 & 0 \\
\hline 108 & 0 & 2 & 0 & 0 & 6 & 0 & 7 & 0 \\
\hline 120 & 0 & 0 & 0 & 0 & 0 & 6 & 0 & 7 \\
\hline
\end{tabular}

Histopathological examination of the lung showed severe inflammatory response in all animals, with presence of interstitial pneumonitis, vascular congestion and inflammatory infiltrate, mainly consisting of neutrophils, in addition to alveolar collapse and vicarious emphysema, indicating a severe systemic inflammatory state. Liver and kidneys are affected in $100 \%$ of cases, with similar pattern to that found in the lung injury, with vascular congestion and polymorphonuclear infiltrate, but without changing the architecture of the organs.

Animals treated with copaiba had lower levels of oxidative stress (Measured by malondialdehyde) (Figure 2 and Table 3) calculated from plasma sample gathered at the time of euthanasia. However, this value was not statistically significant $(\mathrm{p}=0.54$ - Kruskall Wallis test).

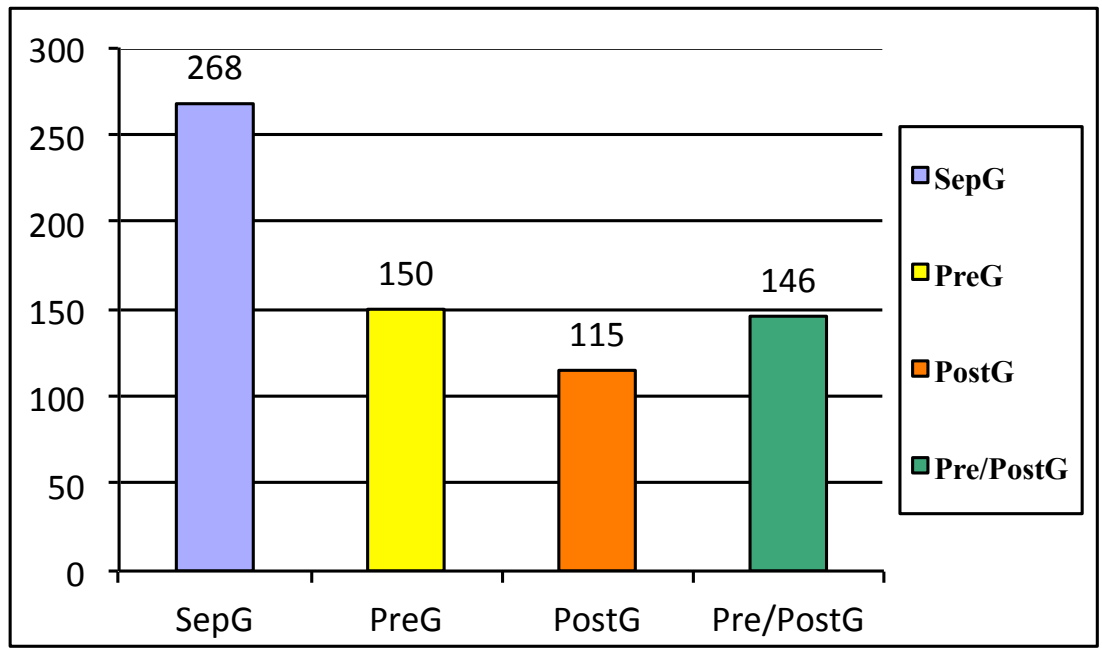

FIGURE 2 - Arithmetic mean of malondialdehyde (MDA) levels, according to the group. $\mathrm{p}>0.05$, Kruskal Wallis. 
TABLE 3 - Absolute value, arithmetic mean and standard deviation of MDA levels according to the study groups.

\begin{tabular}{|c|c|c|c|c|}
\hline Animal/Group & SepG & PreG & PostG & Pre/PostG \\
\hline I & - & 73.029 & 243.430 & 73.029 \\
\hline II & - & 121.715 & - & 73.029 \\
\hline IV & 121.715 & 73.029 & - & 48.686 \\
\hline $\mathrm{V}$ & 97.372 & - & 97.372 & 170.401 \\
\hline VIII & 48.686 & - & 97.372 & 73.029 \\
\hline Arithmetic mean & 267.7736 & 150.4012 & 115.6292 & 146.058 \\
\hline Standard deviation & 330.2056 & 119.6002 & 84.9828 & 136.2631 \\
\hline
\end{tabular}

*Kruskall-Wallis $\mathrm{p}>0.05$

\section{Discussion}

The present study evaluated the organic response of rats with severe sepsis treated prophylactically, and or after the CLP induction. Survival and histopathological findings were described, as well as the levels of oxidative stress, which were compared from the blood collected at the time of death of the animal.

When analyzing the survival curves of the animals submitted to CLP, it is noticed that in each study groups there was a varied period of time in which only few animals died, and then followed by the death of the remainders in a very short period of time. This survival pattern may be related to a final organic decompensation of animals due to the critical state of septicemia in which they were, also demonstrating the similarity of the pathophysiological events that occurred in animals of each group.

Animals receiving prophylactic copaiba, however, were those with the most time to reach the final decompensation period, while the use of copaiba only after CLP led to lower survival, but with no statistical significance when compared to the sepsis group. Is believed then that the anti-inflammatory protective effect occurred only copaiba prophylactically, without providing effect on survival of animals when administered alone after sepsis or increasing some protection together with prophylaxis ${ }^{12,14,17,18}$.

It is known that the main active components responsible for the anti-inflammatory and antimicrobial properties of the copaiba are the diterpenes and sesquiterpenes, as bisabolol and beta betacariofileno ${ }^{15-18}$. However, probably the most important factor to longer animal survival in this study was the anti-inflammatory action of the copaiba oil, by modulating the inflammatory response and subsequent issue damage mediated by free radicals and pro-inflammatory citocins against sepsis, since Santos et al. ${ }^{19}$ demonstrated that Copaifera officinalis does not show effects against gram-negative bacteria and the model of CLP primarily deflagrates gram-negative septicemia.

The MDA was used in order to evaluate the levels of oxidative stress (lipid peroxidation) triggered by the systemic inflammatory condition, and was expected lower levels in groups treated with copaiba, since Castrillo et al. ${ }^{20}$ demonstrated that diterpene kaurene inhibits the nuclear transcription factor $\mathrm{kB}(\mathrm{NF}-$ $\mathrm{kB})$ decreasing macrophage activation. Furthermore, Paiva et al. ${ }^{21}$ and Palva et al. ${ }^{22}$ using the kaurenoic acid found lower levels of MDA in mice with colitis induced by acetic acid.

This study aimed to compare the survival of animals submitted to CLP, however it was decided to not determine a date for euthanasia of animals, since there was the possibility that these remain alive. Thereby, histopathological and oxidative stress analysis were done with organs and blood collected at different times, but all after the immediate death of the animals, which may have given the absence of statistical difference in the analysis of these data, since all animals were in serious condition of health.

Taking into account differences between the animals used for research and humans, extrapolate information obtained in experimental level is not safe, and can, in turn, generate damage. Although animal studies constitute the first level in the clinical research of new drugs, in relation to copaiba, much remains to be evaluated for a future clinical trial is developed. Even if your popular use is widespread, studies on their safety, proper dosage and side effects are still scarce. Another important point to be considered is the great diversity of species and the various active principles present in each one, many still do not isolated. Thus, despite the obvious benefits of crude copaiba oil, its use for clinical treatment still does not appear as a viable measure, it is need studies to assess more accurately the safety of this intervention in human. 


\section{Conclusion}

Prophylactic subcutaneous administration of copaiba (Copaifera reticulada) increases survival of rats subjected to severe sepsis by CLP, being $80 \%$ of animals that received prophylactic copaiba alive after $108 \mathrm{~h}$ CLP while all animals that did not receive it were already dead.

\section{References}

1. Kreimer F, Aguiar JLA, Castro CMMB, Lacerda CM, Reis T, Lisboa Júnior F. Resposta terapêutica e inflamatória de ratos com peritonite secundária submetidos ao uso tópico de ampicilina/ sulbactam. Acta Cir Bras. 2005;20(1):31-9. doi: 10.1590/S010286502005000700007.

2. Valerio TA, Cancelier AC, Constatino L, Petronilho F, Ritter C, Dal-Pizzol F. Inflammatory and oxidative cord blood parameters as predictors of neonatal sepsis severity. Rev Bras Ter Intensiva. 2012 Mar;24(1):30-4. doi: 10.1590/S0103-507X2012000100005.

3. Dellinger RP, Levy MM, Rhodes A, Annane D, Gerlach H, Opal SM, Sevransky JE, Sprung CL, Douglas IS, Jaeschke R, Osborn TM, Nunnally ME, Townsend SR, Reinhart K, Kleinpell RM, Angus DC, Deutschman CS, Machado FR, Rubenfeld GD, Webb S, Beale RJ, Vincent JL, Moreno R. Surviving Sepsis Campaign: international guidelines for management of severe sepsis and septic shock, 2012. Crit Care Med. 2013 Feb;41(2):580-637. doi: 10.1007/ s00134-012-2769-8.

4. Angus DC, van der Poll T. Severe sepsis and septic shock. N Engl J Med. 2013;369:840-51. doi: 10.1056/NEJMra1208623.

5. Siqueira-Batista R, Gomes AP, Calixto-Lima L, Vitorino RR, Perez MCA, Mendonça EG, Oliveira MGA, Geller M. Sepse: atualidades e perspectivas. Rev Bras Ter Intensiva. 2011 Jun;23(2):207-16. doi: 10.1590/S0103-507X2011000200014.

6. Juncal VR, Britto Neto LA, Camelier AA, Messeder OHC, Farias AMC. Impacto clínico do diagnóstico de sepse à admissão em UTI de um hospital privado em Salvador, Bahia. J Bras Pneumol. 2011 Fev;37(1):85-92. doi: 10.1590/S1806-37132011000100013.

7. Benjamim CF. Atualização sobre mediadores e modelos experimentais de sepse. Medicina, Ribeirão Preto. 2001 Mar;34:1826. doi: 10.11606/issn.2176-7262.v34i1p18-26.

8. Veiga Junior VF, Maciel MAM. Plantas medicinais: cura segura? Quim Nova. 2005 Jun;28(3):519-28. doi: 10.1590/S010040422005000300026.

9. Maciel MAM, Pinto AC, Veiga Junior VF, Grynberg NF, Echevarria A. Plantas medicinais: a necessidade de estudos multidisciplinares. Quim Nova. 2002 Maio;25(3):429-38. doi: 10.1590/S010040422002000300016

10. Silveira PF, Bandeira MAM, Arrais PSD. Farmacovigilância e reações adversas às plantas medicinais e fitoterápicos: uma realidade. Rev Bras Farmacogn. 2008 Dez;18(4):618-26. doi: 10.1590/S0102695X2008000400021.

11. Cavalcanti Neto AT, Arruda TEP, Arruda TTP, Pereira SLS, Turatti E. Comparative evaluation between copaiba oil-resin and chlorhexidine digluconate on wound healing. Histological study in rats. Rev Odontol UNESP. 2005 Jun;34(2):107-12.

12. Pieri FA, Silva VO, Souza CF, Costa JCM, Santos LF, Moreira MAS. Antimicrobial profile screening of two oils of Copaifera genus. Arq Bras Med Vet Zootec. 2012 Feb;64(1):241-4. doi: 10.1590/S010209352012000100037 .
13. Leal RA, Fontelles MJP, Rodrigues Neto TS. Copaiba oil effects on survival rate after cecal ligation and puncture in mices. Rev Para Med. 2009 Jan;23(1):33-7.

14. Botelho NM, Silveira EL, Lopes LN, Santos FAF, Teixeira RKC, Silva TTd. Copaiba oil effect under different pathways in mice subjected to sepsis. Acta Cir Bras. 2014 Aug;29(8):528-31. doi: 10.1590/S0102-86502014000800008.

15. Veiga Junior VF, Maciel MAM. Plantas medicinais: cura segura? Quim Nova. 2005 Jun;28(3):519-28.

16. Estevão LRM, Medeiros JP, Baratella-Evêncio L, Simões RS, Mendonça FS, Evêncio-Neto J. Effects of the topical administration of copaiba oil ointment (Copaifera langsdorffi) in skin flaps viability of rats. Acta Cir Bras. 2013 Dec;28(12):863-9. doi: 10.1590/S010286502013001200009 .

17. Teixeira RKC, Yamaki VN, Yasojima EY, Brito, MVH. Effect of copaiba oil in hepatic damage induced by acetaminophen in rats. Acta Cir Bras. 2013 Jul;28(7):526-30. doi: 10.1590/S010286502013000700008

18. Yasojima EY, Teixeira RKC, Houat AP, Costa FLS, Silveira EL, Brito MVH, Lopes Filho GJ. Effect of copaiba oil on correction of abdominal wall defect treated with the use of polypropylene/ polyglecaprone mesh. Acta Cir Bras. 2013 Fev;28(2):131-5. doi: 10.1590/S0102-86502013000200008.

19. Santos AO, Ueda-Nakamura T, Dias FBP, Veiga JVF, Pinto AC, Nakamura CV. Antimicrobial activity of Brazilian copaiba oils obtained from different species of the Copaifera genus. Mem Inst Oswaldo Cruz. 2008 Jan;103(3):277-81. doi: 10.1590/S007402762008005000015.

20. Castrillo A, Heras B, Hortelano S, Rodriguez B, Villar A, Boscá L. Inhibition of the nuclear Factor $\mathrm{kB}(\mathrm{NF}-\mathrm{kB})$ pathway by Tetracyclic Kaurene Diterpenes in macrophages. J Biol Chem. 2001 May;276(19):15854-60. doi: 10.1074/jbc.M100010200.

21. Paiva LA, Cunha KMA, Santos FA, Gramosa NV, Silveira ER, Rao VS. Investigation on the wound healing activity of oleo-resin from Copaifera langsdorffii in rats. Phytother Res. 2002 Dec;16(8):737-9. doi: $10.1002 /$ ptr.1049.

22. Paiva LA, Gurgel LA, De Souza ET, Silveira ER, Silva RM, Santos FA, Rao VS. Protective effect of Copaifera langsdorffii oleo-resin against acetic acid-induced colitis in rats. J Ethnopharmacol. 2004 Jul;93(1):51-6. doi: 10.1016/j.jep.2004.03.028.

\section{Correspondence:}

Marcus Vinicius Henriques Brito

Travessa Apinagés, 630/202

66033-170 Belém - PA Brasil

Tels.: (55 91)3222-9752/98132-6262

marcusvhbrito@gmail.com

Received: Apr 6, 2015

Review: June 11, 2015

Accepted: July 152015

Conflict of interest: none

Financial source: $\mathrm{CNPq}$

${ }^{1}$ Research performed at Experimental Surgery Laboratory, School of Medicine, Universidade Estadual do Pará (UEPA), Belem-PA, Brazil. 